\title{
Dealuminification of Cu-Al-Fe-Ni Alloy by Sea Water Corrosion*
}

\author{
By Gunji Shimoda** and Yoshitsugu Amano***
}

\begin{abstract}
Corrosion in a condenser tube sheet made of $\mathrm{Cu}-\mathrm{Al}-\mathrm{Fe}-\mathrm{Ni}$ alloys was investigated. The matrix constituent between crystals of primary $\alpha$ solid solutions were preferentially corroded, revealing red colour. It was confirmed by an $\mathrm{X}$-ray diffractometer that the red part consists of pure copper, and by X-ray transmission photographs that the direction of its growth coincides with $\langle 001\rangle$, the fibre axis of electroplated copper. Therefore, copper preferentially deposited from the solution containing $\mathrm{Cu}, \mathrm{Al}, \mathrm{Ni}$, etc. From the differences in lattice constants between the $\alpha$ phases before and after corrosion, it was concluded that the compositions of the $\alpha$ phase has a certain range and the concentration of $\mathrm{Al}$ is the lowest in the center of grain.

(Received Apri1 30, 1963)
\end{abstract}

\section{Introduction}

It is well known that JIS H 3208 , a high strength copper alloy, shows high corrosion resistance as well as excellent mechanical properties in a forged state because of the very fine grained structure. The fine grained structure is mainly due to a metallographic process of crystallization, but much improvements can also be done by forging. Although recently large size forging material has been used for various purposes, it is not always easy to get such a fine grained structure. The existence of remaining dentritic structures causes little deterioration in the mechanical properties, but there must be some problems of corrosion resistance. Since a considerable dealuminification was found in a condenser tube sheet of the oil refining equipment, the experiment was made to clarify its mechanism.

\section{Specimen}

The condenser tube sheet is a forged material of 95 $\mathrm{cm}$ in diameter and $4.5 \mathrm{~cm}$ in thickness. The dealuminificated part was cut off from the condenser tube sheet along the chain line as shown in Fig. 1. Remarkable corrosion was observed on the side exposed to the sea water, the velocity being $2.9 \mathrm{ft} / \mathrm{sec}(74$, hole paths) $\sim 4.3 \mathrm{ft} / \mathrm{sec}$ (inlet) and its temperature about $70^{\circ} \mathrm{F}$ (inlet) $\sim 102^{\circ} \mathrm{F}$ (outlet). Corrosion depth of 3 $\mathrm{mm}$ was observed after 157 days running, and reached

* This paper was published in Japanese in the Journal of the Japan Institute of Metals, 26 (1962), 433.

** Department of Applied Physics, Faculty of Engineering, Osaka University, Osaka, Japan.

*** Department of Applied Chemistry, Himeji Institute of Technology, Himeji, Japan.
6 8 mm after 692 days.

\section{Structure of the Corroded Part}

After polishing the corroded part, two-layer structure was observed as shown in Photo. 1. It seems that the corrosion increases gradually until a certain critical depth, then the corrosion is retarded by the surface corrosion product, and again becomes active

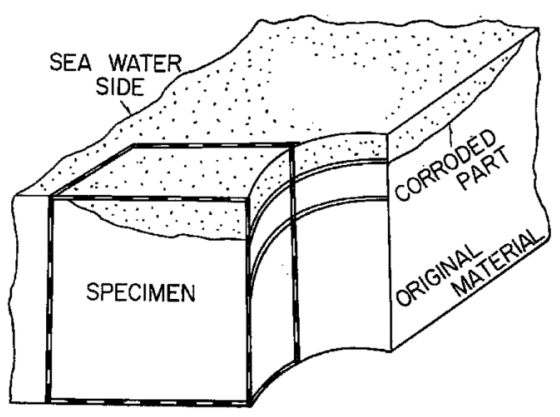

Fig. 1 Specimen.

when the corrosion product is torn off by a mechanical action of flow of the sea water. Therefore the process of corrosion may be repeated periodically.

Vickers hardness values measured were 152 in the original material part and 68.4 and 57.2 in the corroded part, from which it is clear that the greater part of the harder component disappeared by the attack of sea water. After etching the specimen with a solution of ferric chloride and hydrochloric acid, $\alpha$ phase grains of nearly comparable size were observed in both of the corroded and uncorroded parts. Also dealuminificated grains were found between the grains of $\alpha$ phase in the corroded part as shown in Photo. 2. Although the 
dealuminificated particles showed an irregular shape in a dark color, it was not easy to distinguish the dealuminificated particles in the photograph, but it was easily found macroscopically because of its red color. Compositions of the two parts are listed in Table 1 . refined part of grains in the original material might be attributed to a fairly large fluctuation in the composition of $\mathrm{Fe}$, which is the most effective element for refinement of the grains as shown Table 1. Although all the alloying elements were decreased by corrosion as

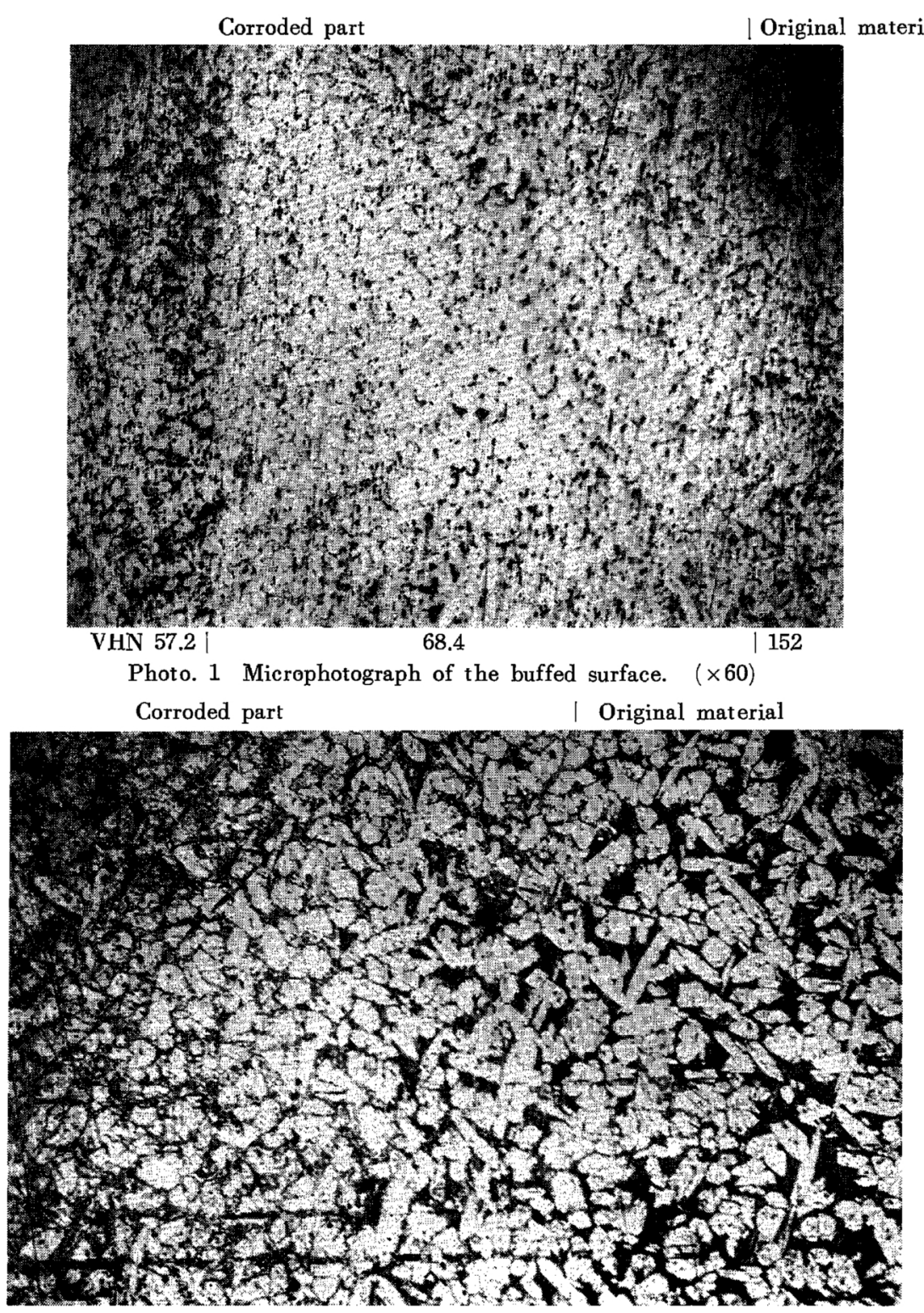

Photo. 2 Microphotograph of the etched surface. $(\times 110)$

Table 1 Compositions of the materials (wt \%).

\begin{tabular}{l|c|c|c|c|c}
\hline \hline & $\mathrm{Al}$ & $\mathrm{Fe}$ & $\mathrm{Ni}$ & $\mathrm{Mn}$ & $\mathrm{Cu}$ \\
\hline $\begin{array}{l}\text { Original } \\
\text { material }\end{array}$ & $\begin{array}{c}9.94 \sim 11.5 \\
(10.78)\end{array}$ & $\begin{array}{c}3.64 \sim 4.57 \\
(4.08)\end{array}$ & $\begin{array}{c}1.11 \sim 1.50 \\
(1.07)\end{array}$ & $\begin{array}{c}1.20 \\
(0.92)\end{array}$ & Balance \\
\hline $\begin{array}{l}\text { Corroded } \\
\text { part }\end{array}$ & $\begin{array}{c}7.61 \\
(7.08)\end{array}$ & $\begin{array}{c}1.79 \sim 2.25 \\
(1.90)\end{array}$ & $\begin{array}{c}0.24 \\
(0.60)\end{array}$ & $\begin{array}{c}0.84 \\
(0.55)\end{array}$ & Balance \\
\hline $\begin{array}{l}\text { Percentage } \\
\text { decrease }\end{array}$ & $\begin{array}{c}29 \\
(34)\end{array}$ & $\begin{array}{c}51 \\
(53)\end{array}$ & $\begin{array}{c}82 \\
(36)\end{array}$ & $\begin{array}{c}32 \\
(40)\end{array}$ & Balance \\
\hline
\end{tabular}

No bracket: Quantometer analysis. Bracket : Chemical analysis.

The results obtained from chemical and quantometric analyses showed good agreement. Since an electric discharge restricted in a localized area is utilized for the quantometric analysis, it is natural that there should be considerable fluctuations in the observed values of a multi-compound alloy. The insufficiently shown in Table 1, the authors wish to call this type of corrosion "dealuminification", because it is a similar phenomenon to the dezincfication of brass and $\mathrm{Al}$ is the principal element of this alloy.

Besides sharp peaks due to $\alpha$ and $\delta$ phases, diffused peaks due to much distorted $\beta^{\prime}$ phase were observed by the X-ray diffractometer as shown in Fig. 2.

After microscopic investigation, $\beta^{\prime}$ was identified as martensitic needles as shown in Photo. 3. Such a needle-like structure must be eliminated by proper heat treatment. But, as heat treatment is rather difficult for such a large specimen, some parts of the intermediate phases may remain martensitic.

\section{Structure of the Dealuminificated Part}

Photo. 4 illustrates the structure at the boundary of the corroded and uncorroded parts. There was no remarkable change in the $\alpha$ phase, while the $\beta^{\prime}+\delta$ 
grains located among $\alpha$ grains were remarkably corroded by sea water, and the new copper-colored crystals produced were observed. X-ray analysis was made to confirm whether this copper colored crystal

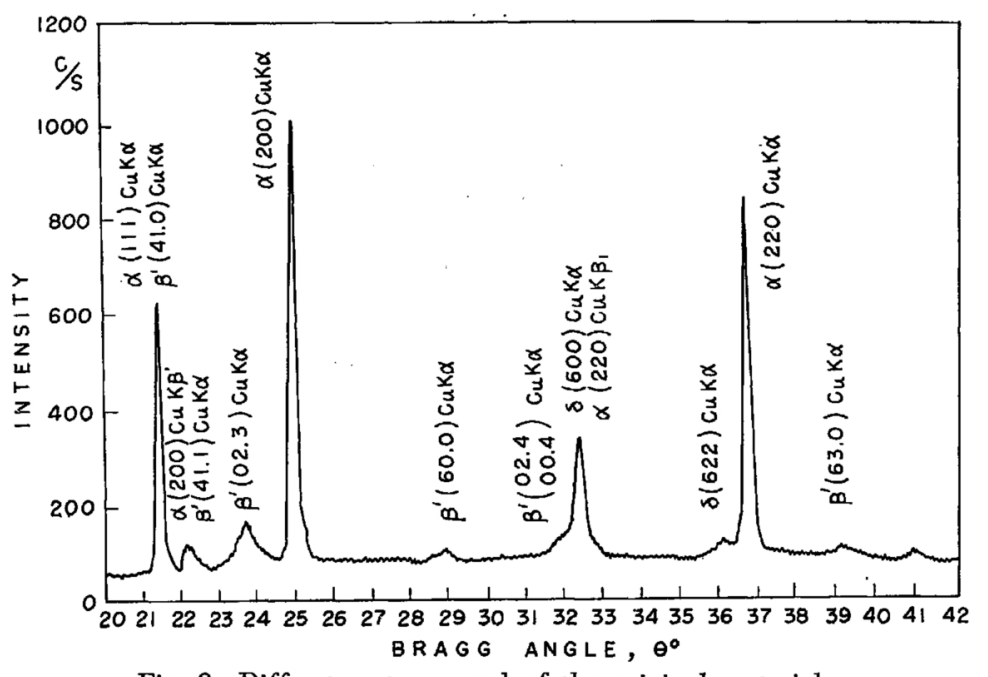

Fig. 2 Diffractometer record of the original material.

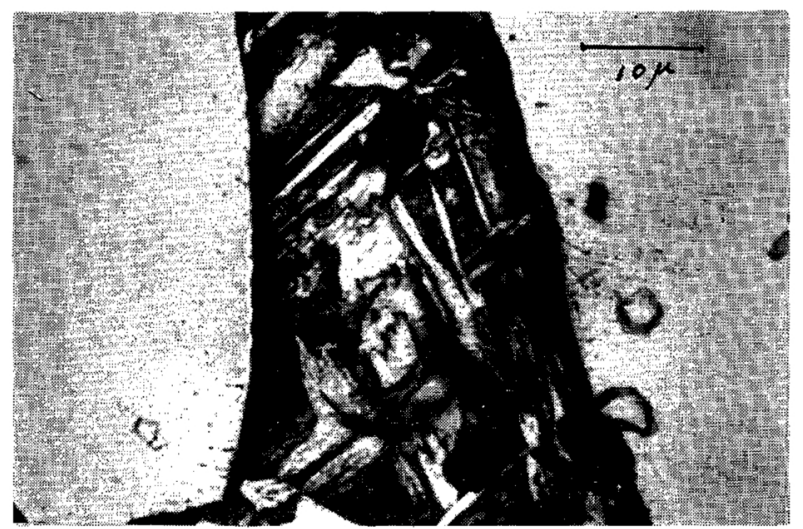

Photo. 3 Microphotograph of the filling between primary $\alpha$.

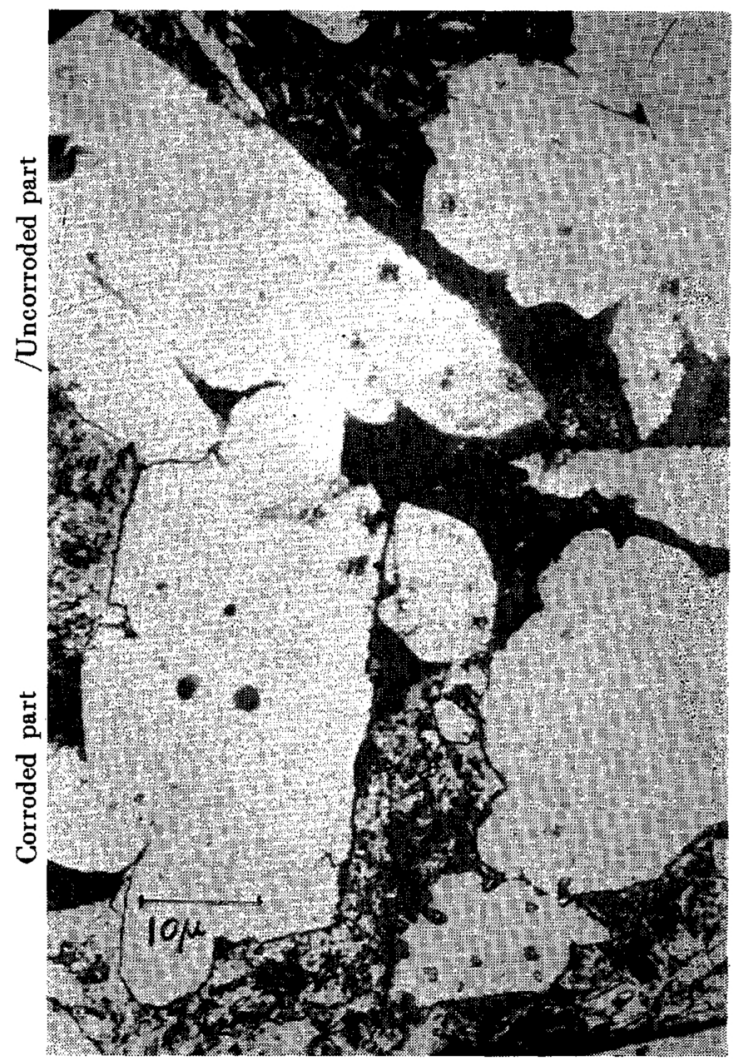

is really pure copper or not, and as shown in Fig. 3, diffraction peaks due to pure copper were clearly recorded in the chart. The amount of copper products was much greater on the sea-water side of the specimen than on the original material side.

The ratios of $\alpha$ to $\mathrm{Cu}$ calculated from the peaks were $3: 1$ and $3: 2$ on the original material side and the sea water side, respectively. Assuming $\alpha$ of $10 \% \mathrm{Al}$ and copper to coexist in the corroded part where the $\alpha$ to $\mathrm{Cu}$ ratio is $3: 2$, the mean concentration of $\mathrm{Al}$ will be $6 \%$ in this region. The Al concentration obtained from the chemical analysis was $7 \%$. Therefore, it is supposed that the variation in $\mathrm{Al}$ concentration exists in the $\alpha$ grains.

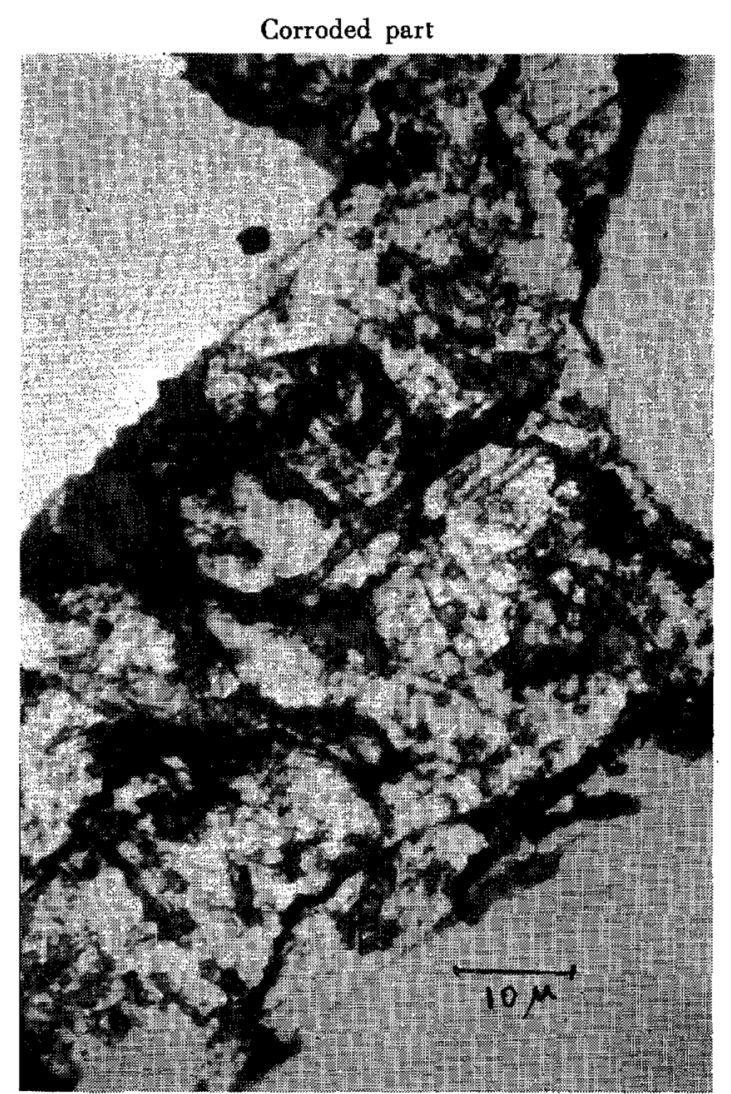

Photo, 4 Boundary between the corroded and uncorroded parts (left hand), and structure of the corroded part (right hand). 
To make clear whether this copper fillings are deposited electrochemically or not, X-ray back reflection photographs were taken. The result is shown in Photo. 5. Small spotty patterns resulted from the $\alpha$ phase remaining in the material, while nearly corroded region.

To determine the fibre axis, pole figures of (111) and (001) were drawn from thirteen sheets of X-ray photographs taken by successively changing the incident beam direction at an angle of $15^{\circ}$ for each

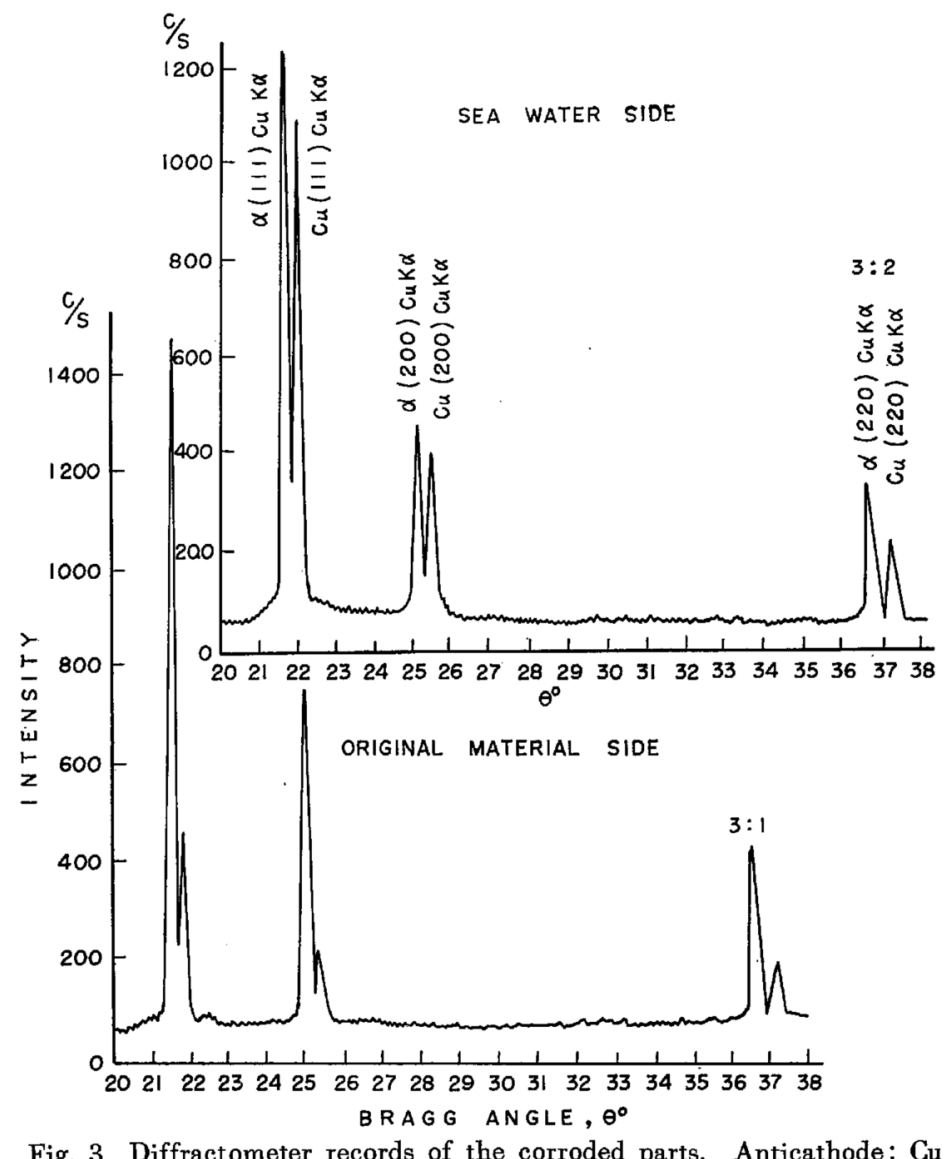

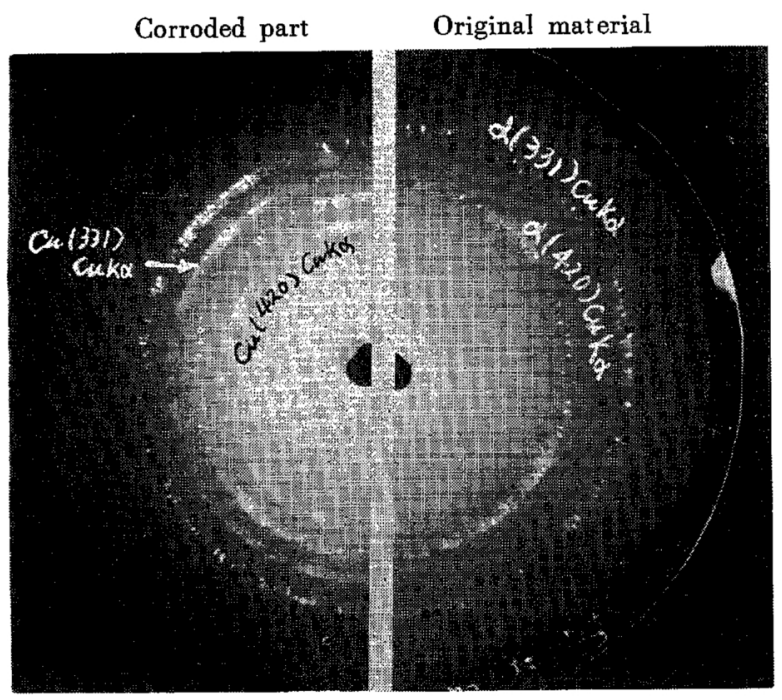

Photo. 5 Back reflection photographs. Anticathode: $\mathrm{Cu}$

continuous rings were obtained from the copper grains emerging after corrosion. The diffraction patterns due to copper grains were quite similar to that obtained from the fine grained electrodeposited metals.

Next, the transmission Laue method was applid to determine its fibrous structure. As shown Photo. 6, quite similar patterns were observed on both the original material side and the sea water side in the photograph. Although a corrosion direction (C. D.) is nearly parallel to $\langle 001\rangle$, a considerable dispersion of orientation seems to exist in it as shown in Fig. 4. As this direction coincides with the direction of growth of the electrodeposited copper(1), it is obvious that the copper is deposited electrochemically.

\section{Structure of $\alpha$ Dentrite}

The diameter of Debye-Scherrer rings, obtained from the $\alpha$ phase in the corroded part as shown in Photo. 5 , was smaller than that of the original material. From their lattice constants, the concentration of aluminium was measured as shown in Table 2. Since the diameter of nickel atom is nearly the same as that of copper, only aluminium has influence on the change in the lattice constant of the solid solution. Therefore, the Al concentration shown in Table 2 may be fairly accurate.

The value of 10.0 percent in the original material is slightly larger than 9:6 percent $^{(2)}$, viz., the solubility limit of aluminium in copper. This slight difference might be attributed to the effect of nickel. The decrease in $\mathrm{Al}$ concentration with the increasing degree

(1) C. S. Barrett: Structure of Metals, (1952), Metallurgy and Metallurgical Engineering Series.

(2) H. Carpenter and J. M. Robertson: Metals, (1939), London. (Oxford Univ. Press) 
of corrosion indicates that the central part of $\alpha$ grain is low in aluminium concentration. Usually, in a solid solution in which the temperature of the liquidus decreases with the increase in the concentration of the alloying element, the concentration of the alloying

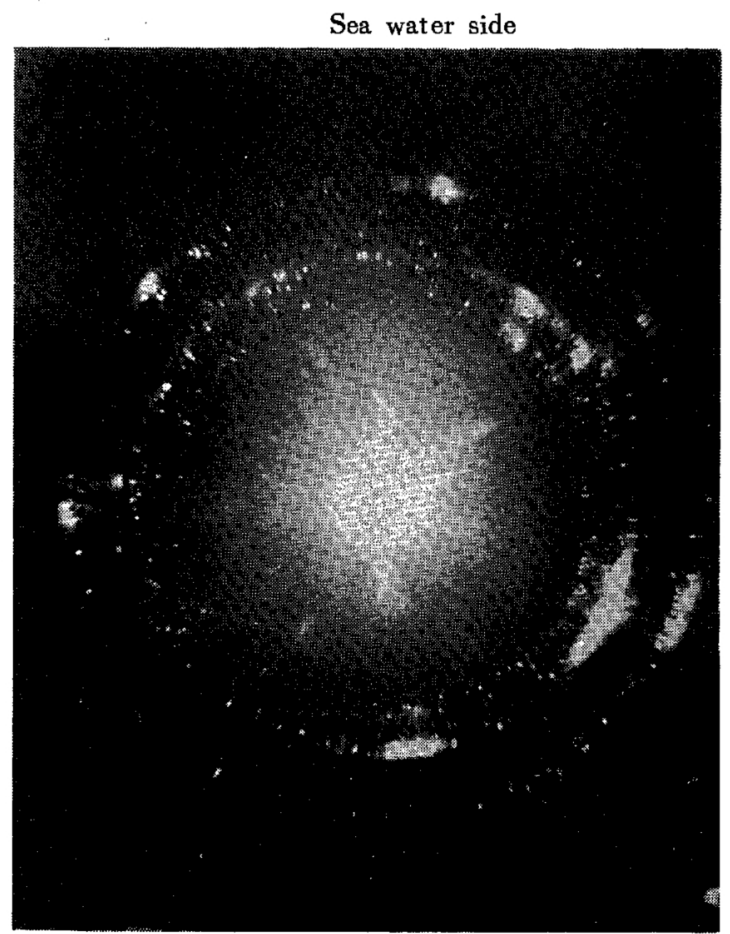

element is the lowest in the initially crystallized region, i.e., the center of the grain or dentrite core. This has been already confirmed with the X-ray method by one of the present authors ${ }^{(3)}$. When the cooling rate is high as in a chill casting, the difference in concentrations

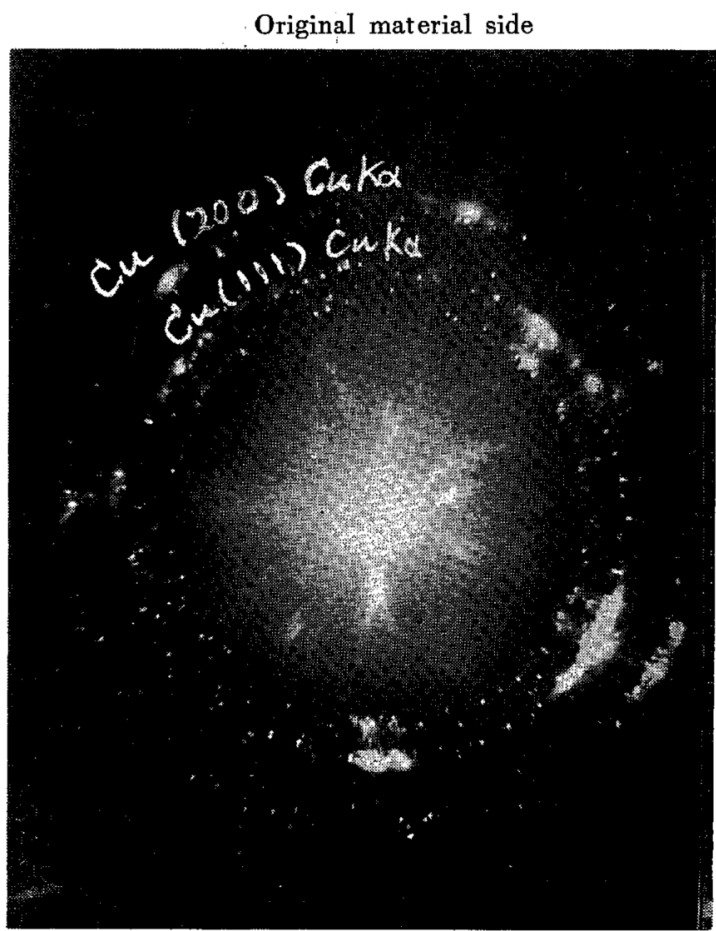

Photo. 6 Transmission Laue photographs of the corroded parts. Anticathode: Cu

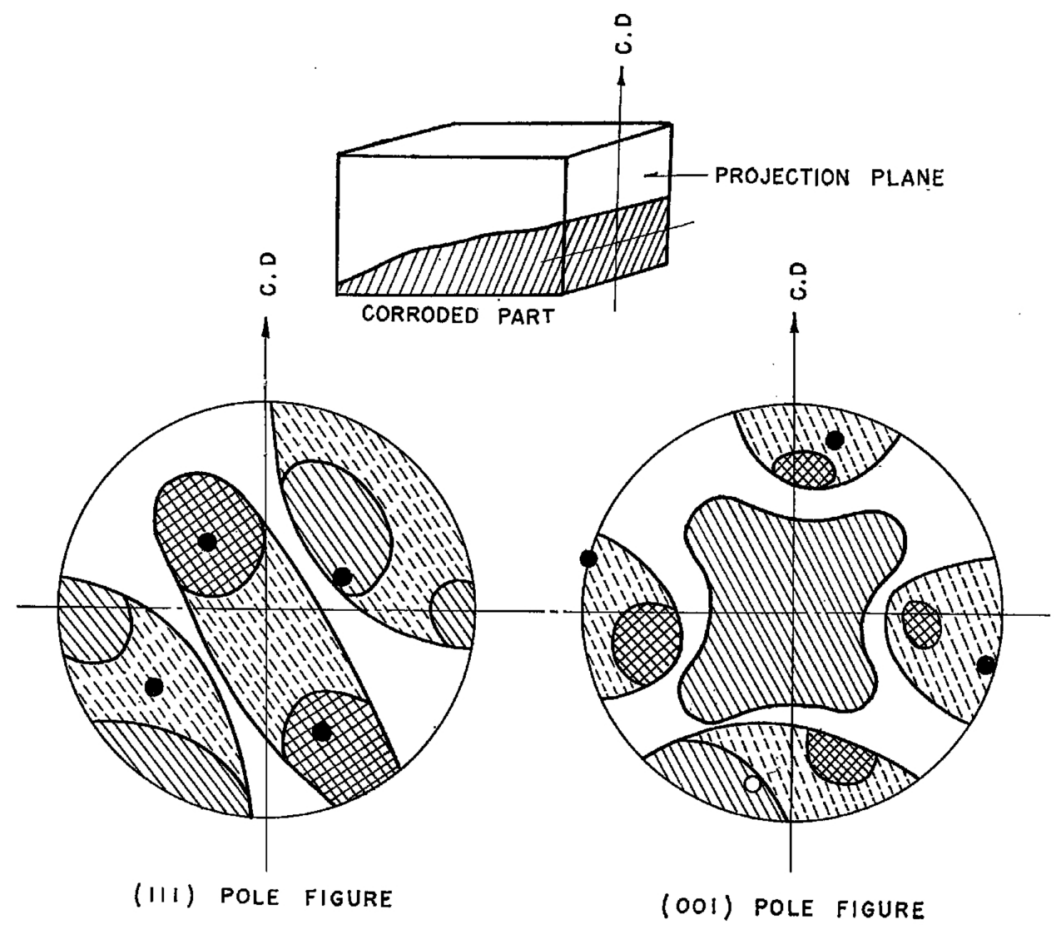

Fig. 4 Pole figures of corroded part. C. D.: corroded direction

Table 2. Lattice constants and Al concentrations of $\alpha$ phase.

\begin{tabular}{l|c|c|c}
\hline \hline & $\begin{array}{c}\text { Original } \\
\text { material }\end{array}$ & \multicolumn{2}{|c}{ Corroded part } \\
\cline { 3 - 4 } & $\begin{array}{c}\text { Near the original } \\
\text { material }\end{array}$ & Near the surface \\
\hline $\begin{array}{l}\text { Lattice } \\
\text { constant A }\end{array}$ & 3.659 & 3.657 & 3.656 \\
$\begin{array}{l}\text { A] \% } \\
\text { computed }\end{array}$ & 10.0 & 9.46 & 9.40 \\
\hline
\end{tabular}

of the alloying element between the dentrite core and its filling materials becames remarkable and this heterogeneity disappears gradually by annealing at a temperature higher than $600^{\circ} \mathrm{C}$. Therefore the decrease in aluminium concentration with the progress of corrosion shows insufficiency of the solution treatment, because the solid solution is attacked from the

(3) G. Shinoda: J. Japan Inst. Metals, 2 (1938), 130 (in Japanese). 
aluminium-rich side of the grain.

Photo. 7 is back reflection photographs of the corroded part, showing diffused Debye-Scherrer rings of $\alpha$ phase. Diffuseness of the rings may be due to ununiformness in the concentration of the alloying ele-

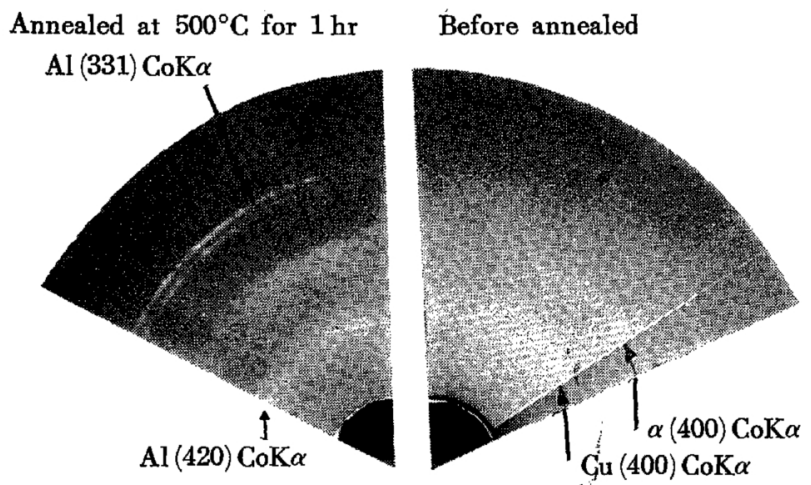

Photo. 7 Large angle back reflection photographs. Anticathode : Co

$\mathrm{Al}(331) \mathrm{CoK} \alpha$ and $\mathrm{Al}(420) \mathrm{CoK} \alpha$ lines are standard lines.

ment or the existence of internal strain. The internal strain may be released by low-temperature annealing. But the sharpness of the ring was not improved by annealing at $500^{\circ} \mathrm{C}$ for $1 \mathrm{hr}$. Therefore, it is clear that the diffuseness of Debye-Scherrer rings must be attributed to heterogeneity of $\alpha$ phase and the original material did not receive proper solution treatment.

Next, an X-ray diffractometeric study was made of two specimens annealed at $550^{\circ} \mathrm{C}$ for $2 \mathrm{hr}$ and annealed at $500^{\circ} \mathrm{C}$ for $20 \mathrm{hr}$ after forging.

As shown in Fig. $5, \alpha+\beta^{\prime}+$ small amount of $\delta$ structure in original material changes gradually to $\alpha+\delta$ structure but the process is not simple. From the newly obtained material, $\beta^{\prime}$ structures of different types were obtained. The new material is the improved one consisting of finer grains. But the problem as to how to control the $\beta^{\prime}$ or $\delta$ structure and the degree of heterogeneity of $\alpha$ phase to obtain a corrosion resistant alloy remains to be further investigated.

\section{Summary}

From the results of research on the dealuminification in a large size forged material of a high strength $\mathrm{Cu}$ Al-Fe-Ni alloy, the following conclusion was obtained:

(1) The product due to dealuminification by the sea water corrosion is copper precipitated electrochemically and growing epitaxially.

(2) The central part of $\alpha$ grain is low in aluminium concentration.

(3) Needle-like $\beta^{\prime}$ phase existing between $\alpha$ grains
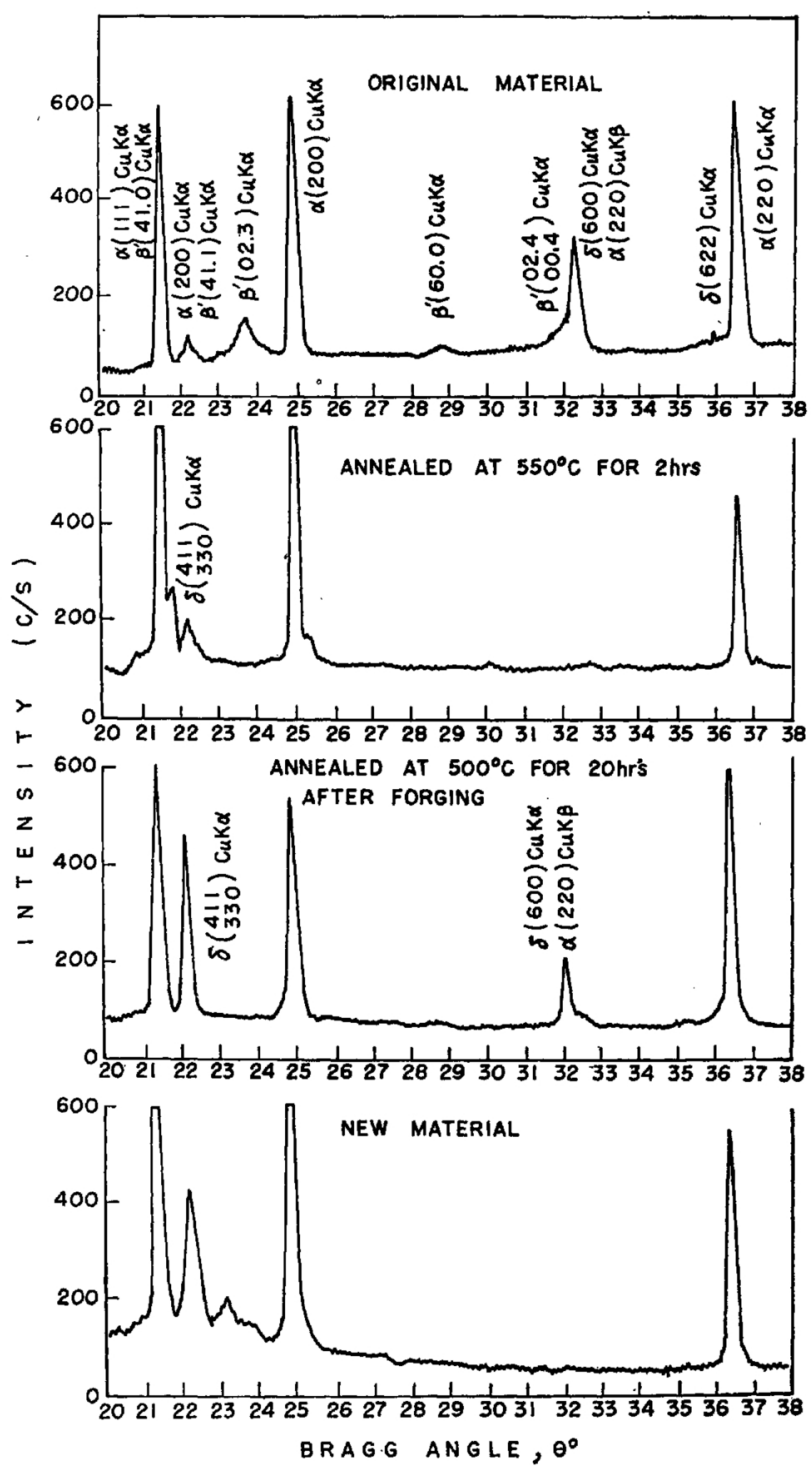

Fig. 5 The effect of different heat treatments on crystal structure.

changes to $\alpha+\delta$ phase gradually by forging and annealing. 